\title{
Evaluation of type 2 diabetes management in Jeddah, Saudi Arabia: a primary care physician's perspective
}

\author{
FAHAD ANWER ${ }^{1, A-G}$, MARWAN ABDULRAHMAN BAKARMAN ${ }^{1, E-G}$, \\ ORCID ID: 0000-0001-7924-5139 ORCID ID: 0000-0002-3515-9850 \\ NADEEM SHAFIQUE BUTT'1, B-E, AHMAD AZAM MALIK 1, 2, A-F \\ ORCID ID: 0000-0002-0473-4920 \\ ORCID ID: 0000-0001-5051-0058
}

\author{
${ }^{1}$ Department of Family and Community Medicine, Faculty of Medicine in Rabigh, King Abdulaziz University, \\ Jeddah, Saudi Arabia \\ ${ }^{2}$ University Institute of Public Health, The University of Lahore, Lahore, Pakistan
}

A - Study Design, B - Data Collection, C - Statistical Analysis, D - Data Interpretation, E - Manuscript Preparation, F - Literature Search, G - Funds Collection

Summary Background. Primary care physicians with an inadequate attitude and practics in managing diabetes may have a detrimental effect on the diabetic patients treated by them. These deficiencies need to be identified so that corrective measures can be planned. Objectives. The aim of the study was to assess the attitude and practices of primary health care physicians of Jeddah City in managing type 2 diabetes mellitus.

Material and methods. This is a cross-sectional quantitative study conducted among primary care physicians in Jeddah, Saudi Arabia. A validated and pretested questionnaire was randomly distributed among physicians working in most of the primary healthcare centers for data collection. Formal ethical approval and informed consent from participants was obtained, and confidentiality was maintained. Results. A total of 225 PCPs working in PHCs of Jeddah participated in the study. 143 of them were male, and most were in the age group of 31 to 40 years. 83 PCPs had work experience of 10-14 years. The lowest score in the attitude section was for choice of the most important modality in DM management. DM management (48\% correct answers), while in the practice section, the lowest score was for instructing patients to inject insulin at the correct angle (36\% correct answers). Age, years of working experience, qualification and current designation showed a significant impact on attitude and practice.

Conclusions. This study has explored several aspects of diabetes related attitude and practices and has emphasized the need for improving the treatment and education of diabetic patients through postgraduate and Continuous Medical Education programs. Key words: attitude, type 2 diabetes mellitus, disease management, primary care physicians.

Anwer F, Bakarman MA, Butt NS, Malik AA. Evaluation of type 2 diabetes management in Jeddah, Saudi Arabia: a primary care physician's perspective. Fam Med Prim Care Rev 2020; 22(4): 273-278, doi: https://doi.org/10.5114/fmpcr.2020.100429.

\section{Background}

Family physicians or general practitioners are the "primary" healthcare providers in most communities. They play an important role in the provision of coordinated primary healthcare (PHC) and make up the basic infrastructure of the healthcare system [1]. In an American survey in 1996, 62\% of Americans reported "primary care physicians" (PCP) as their usual source of care as opposed to $16 \%$ opting for an internist and $15 \%$ for a pediatrician [2]. Type 2 diabetes mellitus (DM) has become one of the most concerning health problem globally, with its prevalence growing to $8.7 \%$ in 2014 [3]. It has been predicted that almost $10 \%$ of the world's population will be diabetic by 2030 [4]. Lifestyle measures and pharmacological measures are thought to reduce the onset of DM among high-risk individuals by half. The increasing prevalence of diabetes and its considerable financial burden requirs timely and efficient screening, diagnoses and treatment [5].

A large burden of chronic diseases can be managed at the primary care level, including Hypertension and Diabetes mellitus. Therefore, primary health care physicians should have adequate skills in managing these chronic disorders [6]. According to the international diabetic federation (IDF), the prevalence of DM in Saudi Arabia in 2017 was 18.5\%, which is considered among the highest in the world [7]. Local and regional studies have suggested that the prevalence of diabetes is around $24 \%$ among Saudi adults [8]. According to a study in 2013, over 6 million Saudis were pre-diabetic/diabetics, with an estimated cost of around 36 billion Riyals per annum [9]. With the increased burden of diabetic patients in Saudi Arabia, the care of diabetic patients has shifted from specialist care to primary care, and subsequently, many chronic disease clinics have been established at different PHCs in Saudi Arabia.

Patients with type 2 diabetes may have acute or chronic comorbid issues that compel physicians to prioritize and manage the symptomatic or presenting problems. Patients with advanced or uncontrolled diabetes may also present with complications, microvascular or macrovascular, in the form of renal, retinal or neurological abnormalities. Furthermore, the condition is worsened by lack of access to a comprehensive multidisciplinary diabetes care team and the incapacity of primary care services in providing continuous care [10]. In many countries, the waiting time for an appointment with an endocrinologist may vary from a few weeks to several months. In countries like Israel, the majority of diabetic patients are diagnosed and managed by PCPs as front-line healthcare providers rather than by diabetologists or endocrinologists [11]. Similarly, the physicians working at the numerous primary health care facilities across KS, make up the first line of patient care, and their knowledge, attitude and practice play a vital role in effective diabetes management.

Optimal care requires PCPs to have the ability to deal with the challenging aspects of DM management, as well as to effectively counsel and educate the patients, since countering 
patients' psychological barriers to disease management is considered vital for improving treatment outcomes [12]. As diabetic patients can present to primary care physicians in different stages of the disease process, as well as with various comorbid conditions, it is essential for PCPs to keep abreast of the updated guidelines and practice the skills for appropriately managing DM patients $[13,14]$.

The attitude and practices of PCPs in DM management can be influenced largely by their early clinical learning and perceptions regarding chronic diseases. Because of deficiencies in training at the undergraduate level, continuing medical education (CME) and postgraduate training thereafter, the PCPs may not be adequately prepared to deliver initial and follow-up care and counseling. Through CME, the physicians remain knowledgeable of the latest guidelines and standards being followed to manage blood sugar levels and the complications of DM.

The standards of diabetic care set by international diabetic associations may not be implemented in all clinical contexts and environments [14], since every healthcare system has its own limitations related to various factors impacting patient management, including the training of physicians, strength of referral systems, etc. The primary health care physician is in an ideal position to influence and manage people with diabetes and assist them in the adoption of lifestyle changes and the prevention of disease complications [15]. However, PCPs face many challenges when caring for people with DM, which are mostly similar in the health care systems of different countries [16]. In Saudi Arabia, PCPs may face some barriers or limitations in the patient care setup, which can compromise diabetic patient care [17].

There are limited studies regarding the aptitude of healthcare providers towards diabetes care in Arab countries. Therefore, there is a need to conduct studies in this regard, as this will help to identify the deficiencies and understand the limitations of primary care physicians in providing diabetic care at a primary care level and improve the system of care and referral for diabetes mellitus. It will also play a vital role in planning and delivering focused educational and training programs to improve the care standards of patients with diabetes mellitus.

\section{Objectives}

This study aims to assess the attitude and practices of the primary health care physicians of Jeddah in managing diabetes mellitus in a primary care setting.

\section{Material and methods}

This study was conducted in Jeddah City in the Kingdom of Saudi Arabia. All primary care physicians working in PHCs were included in the study. The cross-sectional study was conducted from $1^{\text {st }}$ January 2019 to $30^{\text {th }}$ April 2019. Data was collected through simple random sampling. The physicians were recruited from the primary health care centers listed with the health directorate of Jeddah, Ministry of Health. The exact population of primary health care providers working in Jeddah was acquired from the Institute of Public Health of the Jeddah Region, which amounted to 313. A total of 225 PCPs participated in the study, with a response rate of more than $70 \%$. The participating physicians were assured that the results will not be used to appraise their performance in clinical practice.

A questionnaire was prepared by a research team after an extensive relevant literature review. Existing tools used for similar purposes were consulted. In addition, experts were approached to increase tool validity. The questionnaire consisted of three parts. The first concerned background variables data; the second to evaluate the attitude toward DM; and the third for assessing practices in managing DM.

This questionnaire was structured with 10 questions each for assessing attitude towards diabetes management and practices in managing type 2 diabetes mellitus. The questions in the attitude section were derived from two similar studies (JPMA,
Al-Hasa). The questions in the practice section were derived from another study done in Cameroon, as well as from ADA guidelines on DM management. Some of the questions were modified to target the objectives of the study (Questions 1, 4, 5, 6, 7 in the Attitude section and Questions 1, 9 and 10 in the Practice section). The questionnaire was further validated through an expert panel of 5 endocrinologists and then pre-tested by distributing it to the 30 doctors working on a primary care level for better structuring of the questions and removing any discrepancies. This sample of PCPs was not part of the final sample of PCPs included in the study.

The PHCs were identified through the web portal of the Ministry of Health, and a team of surveyors were assigned from Jeddah City to collect data in the PHCs. Formal ethical approval was obtained before data collection from the college ethical review committee. The questionnaires were administered by the research team after taking informed consent. Confidentiality was rigorously maintained. The questions focused on the diagnosis, treatment and complications of DM. The answers of the PCPs were analyzed for their attitude and practices in managing DM. Each question was given one mark for a correct answer, and a zero mark was given for a wrong answer. PCP factors like age, designations, years of experience, etc. influencing the attitude and practice scores were also analyzed.

Data was entered and analyzed using IBM SPSS Statistics for Windows, version 24.0. Categorical data was presented with the help of tables and charts. A tree plot was used to present leading practices. The Kolmogorov-Smirnov test was applied to test the normality of the attitude and practices score. Spearman's Rank correlation was used to determine the strength and direction of correlation between the attitude and practices of DM. The Kruskal-Wallis H-test was used to compare the attitude and practices score by age, experience, designation and source of seeking information.

\begin{tabular}{|l|l|l|l|}
\hline \multicolumn{3}{|c|}{ Table 1. Background variables of primary care physicians } \\
\hline \multirow{2}{*}{ Age } & & $n$ & $\%$ \\
\hline & $23-30$ years & 52 & 23.1 \\
& $31-40$ years & 93 & 41.3 \\
& $41-50$ years & 25 & 11.2 \\
& $51-60$ years & 55 & 24.4 \\
\hline Gender & male & 143 & 63.6 \\
& female & 82 & 36.4 \\
\hline Years of working expe- & $0-4$ years & 38 & 16.9 \\
rience & $5-9$ years & 61 & 27.1 \\
& $10-14$ years & 83 & 36.9 \\
& $>15$ years & 43 & 19.1 \\
\hline Qualification & MBBS & 30 & 13.3 \\
& MBBS + diploma & 62 & 27.6 \\
& MBBS + fellowship & 133 & 59.1 \\
\hline Designation in current & resident & 40 & 17.8 \\
job & general practitioner & 67 & 29.8 \\
& specialist & 89 & 39.6 \\
& consultant & 29 & 12.9 \\
\hline
\end{tabular}

\section{Results}

\section{Background variables of participants}

Data from 225 PCPs was collected for analysis. The response rate was above $70 \%$. Table 1 shows their background variables data, which consisted of 143 male and 82 female physicians. Most of them (41.3\%) were in the age group of 31 to 40 years. 83 PCPs had work experience of 10 to 14 years, followed by 61 having work experience of 5 to 9 years. More than $60 \%$ (121) of PCPs had postgraduate qualifications equivalent to a fellowship. 107 of the participating PCPs were general practitioners, while 89 of them were specialists. The most used resources for updat- 


\begin{tabular}{|c|c|c|c|}
\hline & & $n$ & $\%$ \\
\hline Do you think that type 2 diabetes can lead to serious health consequences if not treated? & $\begin{array}{l}\text { yes* } \\
\text { no } \\
\end{array}$ & $\begin{array}{l}225 \\
0 \\
\end{array}$ & $\begin{array}{l}100.0 \\
0 \\
\end{array}$ \\
\hline Do you believe in primary prevention of type 2 diabetes? & $\begin{array}{l}\text { yes* } \\
\text { no }\end{array}$ & $\begin{array}{l}190 \\
35\end{array}$ & $\begin{array}{l}84.44 \\
15.56\end{array}$ \\
\hline In case type 2 diabetes is under control, will you assess the patient for its possible complications? & $\begin{array}{l}\text { yes* } \\
\text { no }\end{array}$ & $\begin{array}{l}125 \\
100 \\
\end{array}$ & $\begin{array}{l}55.56 \\
44.44 \\
\end{array}$ \\
\hline Do you think type 2 diabetic patients can be treated without medicines? & $\begin{array}{l}\text { yes* } \\
\text { no }\end{array}$ & $\begin{array}{l}116 \\
109 \\
\end{array}$ & $\begin{array}{l}51.56 \\
48.44 \\
\end{array}$ \\
\hline Would you always advise adult obese patients to get screened for type 2 diabetes? & $\begin{array}{l}\text { yes* } \\
\text { no }\end{array}$ & $\begin{array}{l}120 \\
105\end{array}$ & $\begin{array}{r}53.33 \\
46.67 \\
\end{array}$ \\
\hline Clinical practice guidelines should be strictly implemented while managing type 2 diabetes & $\begin{array}{l}\text { yes* } \\
\text { no }\end{array}$ & $\begin{array}{l}129 \\
96\end{array}$ & $\begin{array}{r}57.33 \\
42.67\end{array}$ \\
\hline Would you encourage diabetic patients to self-manage their blood sugar levels? & $\begin{array}{l}\text { yes* } \\
\text { no }\end{array}$ & $\begin{array}{l}194 \\
31\end{array}$ & $\begin{array}{l}86.22 \\
13.78 \\
\end{array}$ \\
\hline Would you advise women with type 2 diabetes to avoid pregnancy? & $\begin{array}{l}\text { yes } \\
\text { no* }\end{array}$ & $\begin{array}{l}13 \\
212 \\
\end{array}$ & $\begin{array}{l}5.78 \\
94.22 \\
\end{array}$ \\
\hline In your opinion, which is the best angle to administer an insulin injection to a diabetic patient? & $\begin{array}{l}15 \text { degrees } \\
45 \text { degrees } \\
90 \text { degrees* }\end{array}$ & $\begin{array}{l}74 \\
28 \\
123 \\
\end{array}$ & $\begin{array}{l}32.89 \\
12.44 \\
54.67 \\
\end{array}$ \\
\hline What would you consider as the most important part of diabetes management? & $\begin{array}{l}\text { oral drugs } \\
\text { insulin } \\
\text { education* }\end{array}$ & $\begin{array}{l}5 \\
112 \\
108\end{array}$ & $\begin{array}{l}2.22 \\
49.78 \\
48.00\end{array}$ \\
\hline
\end{tabular}

\begin{tabular}{|c|c|c|c|}
\hline & & $n$ & $\%$ \\
\hline $\begin{array}{l}\text { Do you routinely advise lifestyle modifications to type } 2 \text { diabetic patients before starting } \\
\text { drug therapy? }\end{array}$ & $\begin{array}{l}\text { every time* } \\
\text { most of the time } \\
\text { sometimes } \\
\text { never }\end{array}$ & $\begin{array}{l}86 \\
109 \\
30 \\
0 \\
\end{array}$ & $\begin{array}{l}38.22 \\
48.45 \\
13.33 \\
0.00 \\
\end{array}$ \\
\hline You instruct your diabetic patients to inject insulin at an angle of & $\begin{array}{l}15 \text { degrees } \\
45 \text { degrees } \\
90 \text { degrees* } \\
\text { do not instruct }\end{array}$ & $\begin{array}{l}26 \\
16 \\
81 \\
102 \\
\end{array}$ & $\begin{array}{l}11.56 \\
7.11 \\
36.00 \\
45.33 \\
\end{array}$ \\
\hline How often do you check the renal function tests of a type 2 diabetic patient? & $\begin{array}{l}\text { every } 3 \text { months } \\
\text { every } 6 \text { months } \\
\text { yearly* } \\
\text { every } 2 \text { years }\end{array}$ & $\begin{array}{l}7 \\
54 \\
152 \\
12 \\
\end{array}$ & $\begin{array}{l}3.11 \\
24.00 \\
67.56 \\
5.33 \\
\end{array}$ \\
\hline Do you refer a type 2 diabetic patient to a nutritionist in your routine practice? & $\begin{array}{l}\text { yes } \\
\text { no } \\
\text { sometimes }\end{array}$ & $\begin{array}{l}74 \\
56 \\
95 \\
\end{array}$ & $\begin{array}{l}32.89 \\
24.89 \\
42.22 \\
\end{array}$ \\
\hline Do you refer your type 2 diabetic patients to endocrinologists in routine practice? & $\begin{array}{l}\text { yes } \\
\text { no } \\
\text { sometimes }\end{array}$ & $\begin{array}{l}187 \\
14 \\
24\end{array}$ & \begin{tabular}{|l}
83.11 \\
6.22 \\
10.67
\end{tabular} \\
\hline
\end{tabular}

ing their knowledge regarding patient care for diabetes mellitus were conferences $(76.5 \%)$, scientific journals $(67.6 \%)$ ant the Internet (64.3\%).

\section{Diabetes related attitude and practice scores of PCPs and their correlation}

Table 2 and 3 shows the distribution of answers to the questions of attitude and practices, respectively. The lowest scores in attitude were observed for questions related for choice of the most important modality in DM management (48\% correct answers), treatment of diabetes without medicines (51.6\% correct answers) and screening all adult obese patients for DM (53.3\% correct answers). Only around 55\% participants considered administering an insulin injection at 90 degrees, which is conforming to the result for the question in practice section which shows that only $36 \%$ physicians instructed the patients to inject insulin at 90 degrees. Only $38.2 \%$ of PCPs advised lifestyle modifications to DM patients at every visit. Around $33 \%$ sent their DM patients to a nutritionist, while $83 \%$ referred them to endocrinologists routinely. The most common reason for referring patients to endocrinologists (approx. 75\%) was insulin therapy (Figure 1). 97.3\% of the physicians prescribed metformin as an initial drug treatment for DM patients.

Table 4 shows the correlation between the median scores of attitude and practices. The overall median attitude score (AS) of physicians was $6.73(\mathrm{SD}=1.609)$. The overall median practice score (PS) of physicians was 7.45 (SD = 1.088). The median attitude and practice scores have a strong positive correlation with each other, with a correlation co-efficient of $0.195(p=0.003)$.

\section{Factors influencing diabetes related attitude and practices}

Table 5 shows the characteristics of physicians which have a significant impact on the attitude and practices related to DM 2 management. These include age, years of working experience, qualification and current designation. 


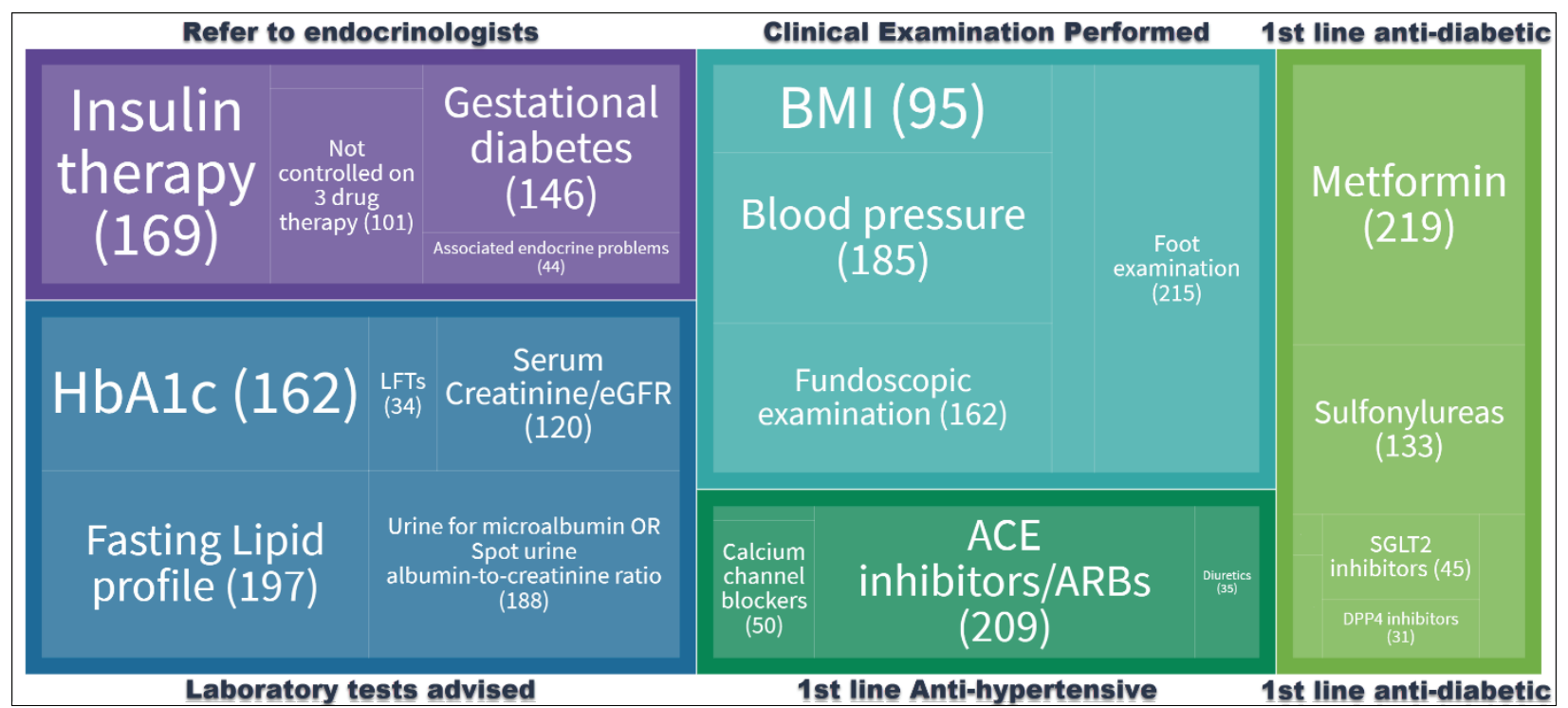

Figure 1. Practices related to clinical examination, investigations and management of DM patients

\begin{tabular}{|c|c|c|c|c|c|c|c|}
\hline & \multirow[t]{2}{*}{ Levels } & \multicolumn{3}{|c|}{ Practices score } & \multicolumn{3}{|c|}{ Attitude score } \\
\hline & & Mean rank & $x^{2}$ & $p$ & Mean rank & $x^{2}$ & $p$ \\
\hline Age & $\begin{array}{l}23-30 \text { years } \\
31-40 \text { years } \\
41-50 \text { years } \\
51-60 \text { years }\end{array}$ & $\begin{array}{l}91.62 \\
109.56 \\
134.69 \\
122.54\end{array}$ & 12.54 & 0.006 & $\begin{array}{l}102.04 \\
99.75 \\
126.14 \\
156.18\end{array}$ & 19.18 & $<0.001$ \\
\hline Experience & $\begin{array}{l}0-4 \text { years } \\
5-9 \text { years } \\
10-14 \text { years } \\
>15 \text { years }\end{array}$ & $\begin{array}{l}83.95 \\
102.11 \\
118.86 \\
142.81 \\
\end{array}$ & 19.02 & $<0.001$ & $\begin{array}{l}111.63 \\
94.89 \\
109.73 \\
146.21 \\
\end{array}$ & 16.68 & $<0.001$ \\
\hline Designation & $\begin{array}{l}\text { general practitioner } \\
\text { specialist } \\
\text { consultant } \\
\text { resident }\end{array}$ & $\begin{array}{l}93.60 \\
127.88 \\
141.00 \\
92.08\end{array}$ & 20.15 & $<0.001$ & $\begin{array}{l}89.26 \\
112.67 \\
178.91 \\
105.71\end{array}$ & 40.44 & $<0.001$ \\
\hline $\begin{array}{l}\text { Seek information from } \\
\text { journals }\end{array}$ & $\begin{array}{l}\text { no } \\
\text { yes }\end{array}$ & $\begin{array}{l}89.84 \\
115.22\end{array}$ & 7.93 & 0.005 & $\begin{array}{l}98.91 \\
110.88\end{array}$ & 1.81 & 0.178 \\
\hline
\end{tabular}

\begin{tabular}{|l|l|l|l|l|}
\hline Table 5. Spearman correlation results between practices score and attitude score \\
\hline Correlation & $r_{\text {s }}$ & Lower & Upper & $p$ \\
\hline Practices score-Attitude score & 0.20 & 0.07 & 0.32 & 0.003 \\
\hline
\end{tabular}

The confidence intervals were computed using $\alpha=0.05 ; n=225$.

With increasing age, there is a marked improvement in both the AS $(p=0.001)$ and PS $(p=0.007)$. The best scores for attitude were observed in the age group of 51-60 years, and for practices $41-50$ years of age. The physicians with more experience in term of the number of years had significantly better AS $(p=0.004)$ and PS $(p=0.00)$. PCPs with more than 15 years of experience has a much better attitude and practices than those in the younger age groups. The lowest attitude score was seen in the group with working experience of 5 to 9 years, while the lowest practice score was observed in those in the working field for 0 to 4 years. PCPs with an additional degree of fellowship after an M.B.B.S (Bachelors in Medicine and Surgery) had better AS $(p=0.026)$ and PS $(p=0.00)$ than those with an M.B.B.S. and diploma, which in turn fared better in AS and PS than those holding an M.B.B.S. degree only.

When correlated with the current designations of PCPs, the consultants fared much better in AS $(p=0.00)$ and PS $(p=0.001)$. They were followed by specialists and general practitioners.
Impact of sources of updates on diabetes-related attitude and practices

Among the various sources used by PCPs to learn updates on diabetes care, scientific journals were found to have a profound effect on the practice score related to DM management $(p=0.028)$, though not on attitude. The other sources of knowledge, including consultants, colleagues, conferences and the Internet, did not show any significant effect on the AS and PS of the participating PCPs.

\section{Discussion}

Primary health care physicians have a vital role to play in caring for and educating diabetic patients. The present study assessed whether PCPs have a satisfactory level of attitude and practice skills to manage DM patients. The results show that there are some important deficiencies in the attitude and practices of Primary health care physicians of Saudi Arabia which need to be addressed. 
In this study, all the PCPs believed that untreated DM can lead to serious consequences. In a Pakistani study, 9 out of 10 participating physicians considered DM as a significant health hazard [18]. It is a known fact that DM causes damage silently at cellular and tissue levels directly, as well as through microvascular and macrovascular injury. It is therefore important to keep blood sugar levels within an optimum range to avoid irreversible target organ damage and reduce morbidity and mortality from DM [19]. In response to a question related to primary prevention of DM, $84 \%$ of the respondents said they see it as playing a definite role, which shows a good attitude score. The percentage is slightly lower than in the Al-Hasa study in Saudi Arabia, which showed around $90 \%$ of physicians believing in primary prevention of DM [20]. Almost $82 \%$ of physicians were of the opinion that women should not avoid pregnancy due to diabetes mellitus. The results are far better than those in a Pakistani study which posed the same question to general practitioners, and $42 \%$ of them agreed that it is safe for diabetic women to become pregnant [18]. It is an established fact that if diabetic mothers-to-be keep their blood sugar levels under control, there is no significant health risk to the fetus or any permanent disability [19].

In this study, the attitude of physicians regarding insulin injection technique was also found lacking. Only $55 \%$ of them would give the insulin injection at the correct angle of 90 degrees. While in their practice, $41.3 \%$ of physicians stated that they do not give instructions for insulin injection, while only $36 \%$ of physicians correctly instructed their patients to perform the insulin injection at 90 degrees. The results are similar to those retrieved by the Al-Hasa study [20] and the Pakistani study on primary care physicians [18], which showed $37 \%$ and $40 \%$ of physicians with correct insulin technique, respectively. It is expected that primary health care physicians who know the correct technique of subcutaneous insulin injection can teach the precise technique to their diabetic patients.

The holistic management of DM consists of both pharmacological and non-pharmacological measures, with non-pharmacological being equally important. In our study, most physicians $(86 \%)$ themselves were advising lifestyle measures every time or most of the time while starting treatment. These results align to those in the Cameroon study [21], in which above $92 \%$ of the PCPs carried out patient counseling for meal planning and regular exercise. In a study in Japan [22], the results were similar to the Cameroon study, with $90 \%$ of physicians regularly advising lifestyle measures. In another study with family physicians, around $95 \%$ of PCPs advised lifestyle changes to DM patients always or often [23].

Only one third of the PCPs in this study referred their diabetic patients to a nutritionist regularly or sometimes as required. The results are in contrast to the Cameroon study [21], in which around $70 \%$ of physicians referred patients regularly to nutritionists for dietary advice. An important factor in this can be the availability of the nutritionists. With limited resources and referral options, PCPs may be compelled to do the dietary counselling themselves, for which they must have adequate knowledge and experience.

There is a high proportion of PCPs referring their patients to endocrinologists for various reasons. The most common reasons were insulin therapy $(90 \%)$ and managing diabetes in pregnant women (78\%). This shows that most of primary health care physicians do not feel comfortable prescribing insulin treatmen, due to lack of knowledge of the principles of insulin therapy. Murray et al. [24] also reported that primary health care physicians do not feel confident in initiating, maintaining and adjusting insulin therapy. In the Yacov study [23], around $33 \%$ of primary health care physicians referred patients needing insulin to endocrinologists. A systematic review concluded that most PCPs lack confidence in knowledge and skills, especially in initiating insulin therapy and facilitating a patient's behavioral change [25].

Regarding initiating drug treatment for DM patients, $97 \%$ of PCPs opted for metformin as the starting drug for $1^{\text {st }}$ line treatment of DM, followed by $59 \%$ choosing sulfonylureas. This approach is in line with the consensus statement of ADA, which recommends starting metformin and lifestyle measures simultaneously [19]. In comparison, the two oral hypoglycemic agents mainly used in the Cameroon study [21] were also metformin (77.3\%) followed by sulfonamides (60.6\%). In our study, more than $90 \%$ of PCPs prescribed an ACE inhibitor to their DM patients as initial therapy. The AHA also recommends using ACE inhibitors or ARBs in the case of diabetes associated with albuminuria [26]. However, all the four major classes of anti-hypertensive drugs are equally useful and effective in the early stages of diabetes with hypertension.

Our results also show that increasing age and years of working experience, better qualifications and seniority in designation leads to significantly improved attitude and practices of DM management. An Iranian study [27] also showed that age and number of clinical years have a strong correlation with good attitude and practices. Among the sources of seeking updates related to $D M$, reading scientific journals has shown to have a great impact in improving the practices of PCPs of DM. This reflects that PCPs should be given more access to scientific journal to get the most authentic knowledge related to DM diagnosis and treatment.

\section{Limitations of the study}

Firstly, the responses are very subjective and may not fully reflect actual management practices. Secondly, our results cannot be generalized to the entire population of Saudi PCP, as we recruited only PCPs working in the city of Jeddah, and they may differ from the larger macrocosm of practicing PCPs in KSA.

\section{Conclusions}

This study has explored several aspects of the diabetes-related attitude and practices of PCPs working in primary health care centers affiliated with the Ministry of Health. It has recognized the need for improvement in their attitude and practices for educating and treating the DM patients attending their clinics. The PCPs should have sufficient skills in prescribing and giving instructions for insulin therapy to their patients. This will not only benefit patient care, but it will also decrease referrals and overall patient load on endocrinologists. PCPs should be encouraged to do post-graduation training, attend related CME activities and access scientific journals to keep themselves updated.

Acknowledgments. The authors acknowledge, with thanks, the DSR (Deanship of Scientific Research) for technical and financial support. We would like to thank the students of Rabigh Medical College, Abdulrahman A. Makeen, Abdulrahman M. Al Mutiri and Abdulrahman A. Alghamdi for their assistance in carrying out the survey and technical support and acknowledge the efforts of the female students of King Abdulaziz University, Noura A. Alsulami, Sara M. Alkhammash and Raghad K. Aldhahri, for their contribution in data collection. 


\section{References}

1. Montegut AJ, Schirmer J, Cartwright C, et al. Creation of postgraduate training programs for family medicine in Vietnam. Fam Med 2007; 39(9): 634-638.

2. Fryer G. The importance of having a usual source of care. Am Fam Physician 2000; 62: 477.

3. World Health Organization. Global report on diabetes. WHO; 2016.

4. Whiting DR, Guariguata L, Weil C, et al. IDF diabetes atlas: global estimates of the prevalence of diabetes for 2011 and 2030 . Diabetes Res Clin Pract 2011; 94(3): 311-321.

5. Tuomilehto J, Lindström J, Eriksson JG, et al. Prevention of type 2 diabetes mellitus by changes in lifestyle among subjects with impaired glucose tolerance. N Engl J Med 2001; 344(18): 1343-1350.

6. Hudon C, Fortin M, Haggerty J, et al. Patient-centered care in chronic disease management: a thematic analysis of the literature in family medicine. Patient Educ Cuns 2012; 88(2): 170-176.

7. IDF. The International Diabetes Federation (IDF) Middle East and North Africa (MENA) Region 2019 [cited 30.03.2020]. Available from URL: https://idf.org/our-network/regions-members/middle-east-and-north-africa/members/46-saudi-arabia.html.

8. Al-Nozha MM, Al-Maatouq MA, Al-Mazrou YY, et al. Diabetes mellitus in Saudi Arabia. Saudi Med J 2004; 25(11): $1603-1610$.

9. Alhowaish AK. Economic costs of diabetes in Saudi Arabia. J Family Community Med 2013; 20(1): 1-7.

10. Spann SJ, Nutting PA, Galliher JM, et al. Management of type 2 diabetes in the primary care setting: a practice-based research network study. Ann Fam Med 2006; 4(1): 23-31.

11. Goldfracht M, Levin D, Peled O, et al. Twelve-year follow-up of a population-based primary care diabetes program in Israel. Int J Qual Health Care 2011; 23(6): 674-681.

12. Peyrot $\mathrm{M}$, Rubin R, Lauritzen $\mathrm{T}$, et al. Psychosocial problems and barriers to improved diabetes management: results of the Cross? National Diabetes Attitudes, Wishes and Needs (DAWN) Study. Diabet Med 2005; 22(10): 1379-1385.

13. Hofer TP, Zemencuk JK, Hayward RA. When there is too much to do: how practicing physicians prioritize among recommended interventions. J Gen Intern Med 2004; 19(6): 646-653.

14. Wagner EH, Austin BT, Davis C, et al. Improving chronic illness care: translating evidence into action. Health Aff (Millwood) 2001; 20(6): 64-78.

15. Hilts L, Howard M, Price D, et al. Helping primary care teams emerge through a quality improvement program. Fam Pract 2013; 30(2): 204-211.

16. Ziemer DC, Miller CD, Rhee MK, et al. Clinical inertia contributes to poor diabetes control in a primary care setting. Diabet Educ 2005; 31(4): 564-571.

17. Alsaleem MAS. Assessment of primary health care physicians' knowledge and practice about diabetes mellitus in aseer region, KSA. KKU Journal of Medical Sciences 2017; 2(1): 1-8.

18. Shera A, Jawad F, Basit A. Diabetes related knowledge, attitude and practices of family physicians in Pakistan. J Pak Med Assoc 2002; 52(10): 465-470

19. American Diabetes Association. Standards of medical care in diabetes - 2018 abridged for primary care providers. Clinical Diabetes Care 2018; 36(1): 14-36.

20. Khan $\mathrm{A}$, Lateef $\mathrm{N}$, Khamseen $\mathrm{M}$, et al. Knowledge, attitude and practice of ministry of health primary health care physicians in the management of type 2 diabetes mellitus: a cross sectional study in the Al Hasa District of Saudi Arabia, 2010. Niger J Clin Pract 2011; 14(1): 52-59.

21. Jingi AM, Nansseu JRN, Noubiap JJN. Primary care physicians' practice regarding diabetes mellitus diagnosis, evaluation and management in the West region of Cameroon. BMC Endocr Disord 2015; 15(1): 18.

22. Morishita Y, Miki A, Okada M, et al. Exercise counseling of primary care physicians in metabolic syndrome and cardiovascular diseases is associated with their specialty and exercise habits. Int J Gen Med 2014; 7: 277-283.

23. Fogelman $\mathrm{Y}$, Goldfracht $\mathrm{M}$, Karkabi K. Managing diabetes mellitus: a survey of attitudes and practices among family physicians. J Community Health 2015; 40(5): 1002-1007.

24. Murray S, Lazure P, Schroter S, et al. International challenges without borders: a descriptive study of family physicians' educational needs in the field of diabetes. BMC Fam Pract 2011; 12(1): 27.

25. Rushforth B, McCrorie C, Glidewell L, et al. Barriers to effective management of type 2 diabetes in primary care: qualitative systematic review. Br J Gen Pract 2016; 66(643): e114-e127.

26. Reboussin DM, Allen NB, Griswold ME, et al. Systematic review for the 2017 ACC/AHA/AAPA/ABC/ACPM/AGS/APhA/ASH/ASPC/NMA/ PCNA guideline for the prevention, detection, evaluation, and management of high blood pressure in adults: a report of the American College of Cardiology/American Heart Association Task Force on Clinical Practice Guidelines. J Am Coll Cardiol 2018; 71: $2176-2198$.

27. Aghili R, Malek M, Peyvandi AA, et al. General Practitioners' knowledge and clinical practice in management of people with type 2 diabetes in Iran; the impact of continuous medical education programs. Arch Iran Med 2015; 18(9): 582-585.

Tables: 5

Figures: 1

References: 27

Received: 24.04 .2020

Reviewed: 28.04 .2020

Accepted: 1.06 .2020

Address for correspondence:

Fahad Anwer, FCPS, MRCGP (Int.)

Department of Family and Community Medicine

Faculty of Medicine in Rabigh

King Abdulaziz University

P.O. Box 80200 Jeddah

Saudi Arabia

Tel.: +96 6581080233

E-mail: drfahad101@gmail.com 